\title{
Live birth rate after IVF/ICSI in women with low and extremely low AMH: an age- matched controlled study
}

\author{
Yomna I. Zaghloul ${ }^{1,2^{*}}$ (D), Yahia M. Amin ${ }^{1}$, Ragaa T. Mansour ${ }^{1}$, Ahmed Serour ${ }^{1,3}$, Mona M. Aboulghar ${ }^{1,2}$, \\ Mohamed A. Aboulghar ${ }^{1,2}$ and Gamal I. Serour ${ }^{1,3}$
}

\begin{abstract}
Background: An age-matched controlled study, to assess the outcome of IVF/ICSI in low and extremely low AMH levels in different age groups by comparing the live birth rate

Materials and methods: An age-matched controlled study was done at the Egyptian IVF center, Cairo, Egypt, including 306 infertile women with low AMH levels undergoing IVF/ICSI and an age-matched number of women with normal $\mathrm{AMH}$. The live birth rate in the different age groups according to the AMH level was compared.

Results: There was no significant difference between LBR in the extremely low AMH arm (11.43\%) and low AMH (16.4\%) $(P=0.24)$. The LBR was $30.4 \%$ in women with normal AMH as compared to $14.7 \%$ in all women with AMH below $1 \mathrm{pg} / \mathrm{ml}(P=0.002)$.

The LBR was significantly higher in women below the age of 35 years and women of 35-40 years with normal AMH (33.2\% and 31.7\%) as compared to LBR in the corresponding age groups with low AMH (18.6\% and 13.3\%).

Conclusions: There was no difference in the outcome of IVF between patients with low and extremely low AMH levels. Women with normal AMH level resulted in a higher pregnancy rate as compared to women with low AMH level in the same age group. Age is important in determining prognosis of IVF in patients with low levels of AMH.
\end{abstract}

Keywords: AMH, IVF/ICSI, Pregnancy rates, LBR, Age

\section{Background}

Anti-Müllerian hormone (AMH) is a dimeric glycoprotein, a member of the transforming growth factor (TGF)-b superfamily [1]. In women, AMH is produced by the granulosa cells (GC) in the preantral and antral follicles [2]. Because serum AMH levels reflect the ovarian follicular pool, any reduction in the number of small, growing follicles may be followed by a reduction in the circulating $\mathrm{AMH}$ [3]. AMH is a better marker of the ovarian reserve than age alone and is superior to other markers described in the literature, such as basal FSH, E2, and inhibin B [4]. Age clearly remains the primary determinant of the probability of a live birth after

\footnotetext{
* Correspondence: yomnaizaghloul@gmail.com

${ }^{1}$ The Egyptian IVF Center, 3 Street No. 161 Hadayek El-Maadi, Cairo 11431 Egypt

${ }^{2}$ Faculty of Medicine, Cairo University, Cairo, Egypt

Full list of author information is available at the end of the article
}

assisted conception, but for any given age, women with higher ovarian reserve and therefore higher circulating $\mathrm{AMH}$ levels have a higher success rate than their counterparts with lower AMH [5].

The objective of this work was to study the outcome of IVF/ICSI in infertile women with low AMH levels and extremely low AMH levels in different age groups.

\section{Methods}

During the period from January 1, 2015, to March 31, 2016, a total of 390 women with low level of AMH were counseled for IVF/ICSI. AMH was considered to be low with levels $1 \mathrm{ng} / \mathrm{ml}$ and below. Levels below $0.5 \mathrm{ng} / \mathrm{ml}$ were considered extremely low level. Eighty-four women decided not to be enrolled in the IVF/ICSI program after explaining the poor prognosis in their individual cases. Most of this group had a very low $\mathrm{AMH}$, and their age was above 39 years old. 
We enrolled 306 women with low AMH level into our IVF/ICSI program (group A). Group A $(n=306)$ was subdivided into group A1 (patients below 35 years old, $n$ = 156), group A2 (patients from 35-40 years old, $n=$ 113 ), and group A3 (patients above 40 years old, $n=37$ ). An age-matched equal number of patients (group $\mathrm{B}, n=$ 306) were selected from patients who underwent IVF/ ICSI during the same period, and they had AMH levels above $1 \mathrm{ng} / \mathrm{ml}$. Group B was also divided according to the same age group as in GA into three subgroups similar in number, named groups B1, B2, and B3 (Table 3).

All patients in both groups signed our informed consent. Routine AMH was performed for all patients (Beckman Coulter Kit, Beckman Coulter) using the Gen II assay [6].

All enrolled women in group A $(n=306)$ were treated by the ultrashort protocol of ovarian stimulation. Subcutaneous $\mathrm{GnRH}-\mathrm{a}(0.1 \mathrm{mg})$ was given daily from the first day of the cycle for 3 days, and $450 \mathrm{IU}$ of RecFSH (Gonal F) or hMG Gonapure (Ferring) was injected daily from day 3 of the cycle. Human chorionic gonadotropin (Choriomon 10,000 IU, IBSA) was given when the leading follicle reached $17 \mathrm{~mm}$. Luteal phase support in the form of $400 \mathrm{mg}$ vaginal natural progesterone (Prontogest, IBSA) was provided. The criteria for cycle cancelation were the presence of less than three follicles with an E2 level less than $400 \mathrm{pg} / \mathrm{ml}$. Women in group B $n=$ 306 were treated with our routine long $\mathrm{GnRH}$-a protocol which was published before [3].

Ethical approval was obtained from The Internal Ethical committee of the Egyptian IVF Center in December 2014 (approval number: 2014/017).

The study outcome was to compare the live birth rate in the different age groups according to the AMH level.

\section{Statistical analysis}

Data were statistically described in terms of mean \pm standard deviation $( \pm \mathrm{SD}$ ), $95 \% \mathrm{CI}$, frequencies (number of cases), and percentages when appropriate. Comparison of numerical variables between the study groups was done using the Student $t$ test for independent samples in comparing two groups of normally distributed data and the Mann-Whitney $U$ test for independent samples for comparing not normal data. For comparing categorical data, the chi-square $\left(\chi^{2}\right)$ test was performed. The exact test was used instead when the expected frequency is less than 5. $P$ values less than 0.05 were considered statistically significant. All statistical calculations were done using computer program IBM SPSS (Statistical Package for the Social Science; IBM Corp, USA) release 22 for Microsoft Windows.

\section{Results}

There was no significant difference in mean age between groups A and B (Table 1). The mean level of AMH in group A $(0.59 \pm 0.25)$ was significantly lower than the mean level of group B $(3.93 \pm 2.74)(95 \%$ CI -3.642 to - 3.0243).

In group $\mathrm{A}$, the mean number of oocytes retrieved was $5.74 \pm 3.71$ and the mean number of cleaved embryos was $3.51 \pm 2.394$ as compared to $12.69 \pm 6.10$ and $5.77 \pm$ 3.51 in group B respectively (Table 1, Figs. 1, 2, 3 and 4).

The number of women who did not retrieve oocytes was 7 in group A and 1 in group B. The number of patients who achieved embryo transfer was 228 (74.5\%) in group A and $287(93.8 \%)$ in group B $(<0.001)$ (Table 1). The clinical pregnancy rate and the live birth rate per started cycle were $19.6 \%$ and $14.7 \%$ in group A as compared to $35.9 \%$ and $30.4 \%$ in the control group B respectively, $P$ value $<0.05$ (Table 1 ).

There was no significant difference in clinical and live birth rates between patients with AMH levels below 0.5 $\mathrm{ng} / \mathrm{ml}$ as compared to AMH levels above 0.5 and below $1 \mathrm{ng} / \mathrm{ml}$ (Table 2).

In patients with very low $\mathrm{AMH}$, the clinical pregnancy and the live birth rates were $17 \%$ and $11 \%$ as compared to $21 \%$ and $16 \%$ in women with $\mathrm{AMH}$ between 0.5 and $1 \mathrm{ng} / \mathrm{ml}$ respectively. The difference was not significant (Table 2).

Table 1 Clinical outcome in women with normal and low AMH levels

\begin{tabular}{llll}
\hline & AMH $\leq 1$ & AMH $>1$ & 306 \\
\hline Number of women & 306 & $3.93 \pm 2.74$ \\
Mean AMH (ng/ml) & $0.59 \pm 0.25$ & $33.05 \pm 5.77$ \\
Mean age (years) & $33.79 \pm 4.93$ & $12.69 \pm 6.106$ \\
Mean number of oocytes retrieved & $5.74 \pm 3.71$ & $5.77 \pm 3.51$ \\
Mean number of cleaved embryos & $3.51 \pm 2.39$ & $287(93.8 \%)$ \\
Number of patients who had embryo transfer & $228(74.5 \%)$ & 1 & $<0.001$ \\
Number of patients with no oocytes retrieved & 7 & $110(35.94 \%)$ & $<.001$ \\
Clinical pregnancy rate per started cycles & $60(19.6 \%)$ & $93(30.4 \%)$ & $<.001$ \\
Live birth rate per started cycles & $45(14.7 \%)$ & & 0.002 \\
\hline
\end{tabular}




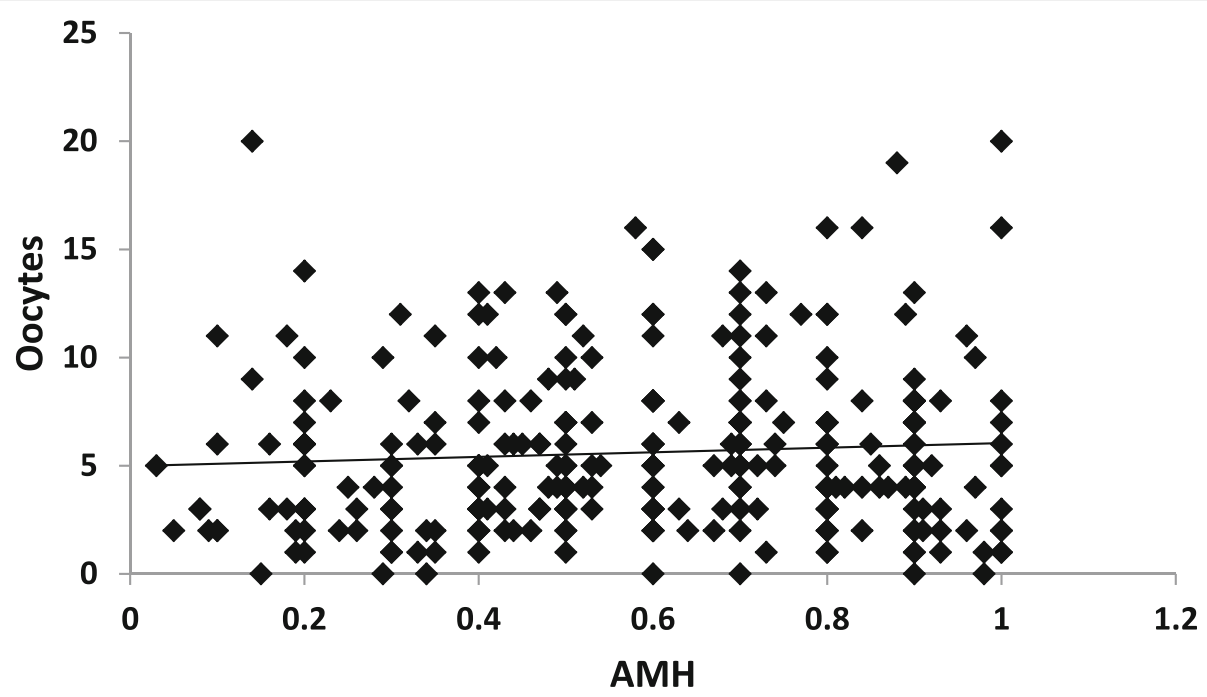

Fig. 1 Correlation between AMH level and total oocytes among cases with $\mathrm{AMH}<1$

The mean number of oocytes retrieved, mean number of cleaved embryos, number of patients who had embryo transfer, and number of patients with total failure of fertilization in groups A and B in all age subgroups are presented in Table 3.

\section{Discussion}

The present study has shown that both age and AMH are important factors for determining the outcome of IVF/ICSI. Comparing an age-matched group of women with normal $\mathrm{AMH}$ level to the study group, the mean clinical and live birth rates were significantly higher in women with normal AMH. This denotes that low AMH reduces pregnancy rates in IVF/ICSI patients at all age groups. However, there was no significant difference in clinical or live birth rates between the low and the extremely low $\mathrm{AMH}$, in the same age group. In women with low level of $\mathrm{AMH}$, age became the most important prognostic factor and not how low AMH level is.

Based on this study, the age becomes the crucial factor during counseling. Even one or two oocytes can result in a reasonable pregnancy rate in this group of young women.

$\mathrm{AMH}$ has been gaining popularity as its intra-cycle stability makes it a more convenient tool $[7,8]$.

Evidence is accumulating suggesting that AMH is the best currently available test in terms of sensitivity and specificity. However, it should be combined with age, to

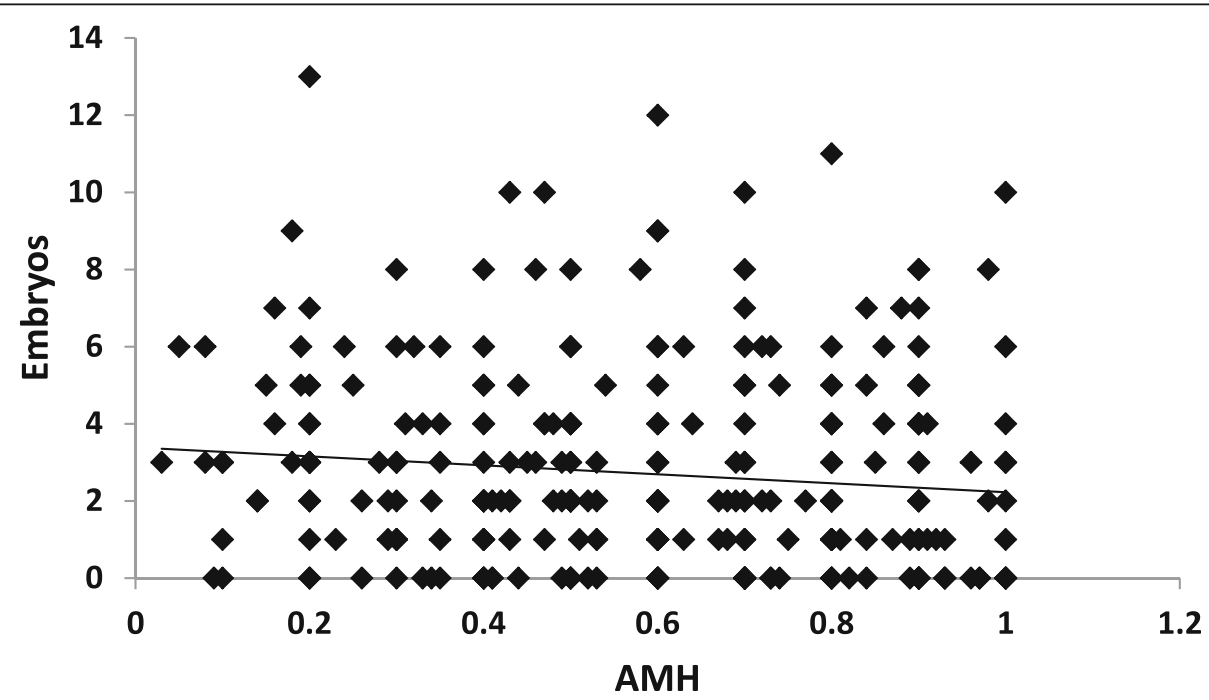

Fig. 2 Correlation between $\mathrm{AMH}$ level and total embryos among cases with $\mathrm{AMH}<1$ 


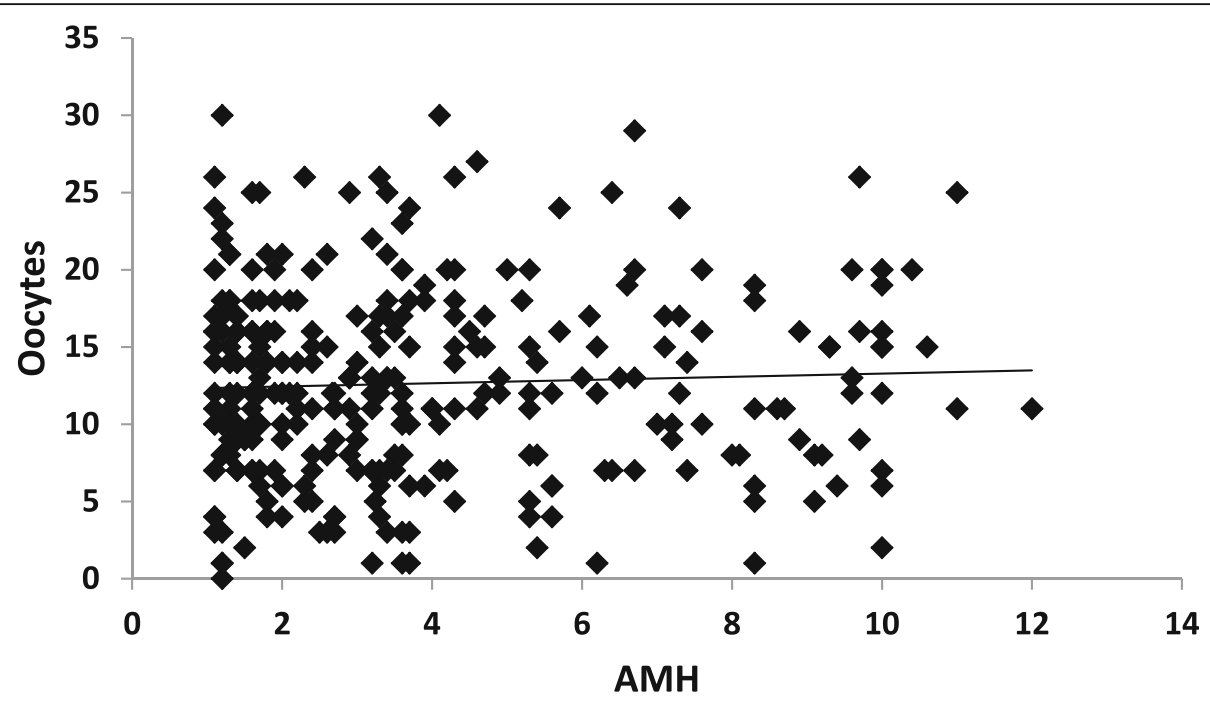

Fig. 3 Correlation between AMH level and total oocytes among cases with $\mathrm{AMH}>1$

allow for a better assessment of the fertility potential of a given woman [9].

The immediate clinical implication of the present finding is that AMH combined with age provides strong information for couples considering assisted reproduction. However, its diagnostic accuracy in live birth alone is poor and could not be used to alter clinical decisions. Adoption of an AMH threshold for access to assisted reproduction was not possible in our study as the live birth rate in the same age group did not differ between low and very low AMH levels.

Several studies evaluated the outcome of IVF/ICSI in extremely low levels of AMH. It was reported in a study with 101 women and 188 embryos with extremely low $\mathrm{AMH}$ levels (below $0.4 \mathrm{ng} / \mathrm{ml}$ ) that pregnancy can be achieved in this group and AMH helped to counsel the patients [10]. In another study, the chance of pregnancy and the number of obtained embryos, high-quality embryos, and transferred embryos were positively correlated with the level of AMH. Therefore, it might be argued that the correlation between AMH and pregnancy depends on the number of obtained oocytes and embryos available for transfer, rather than embryo quality. So, although AMH levels might compromise pregnancy outcomes, lower levels of AMH do not impair the embryo developmental competence [11].

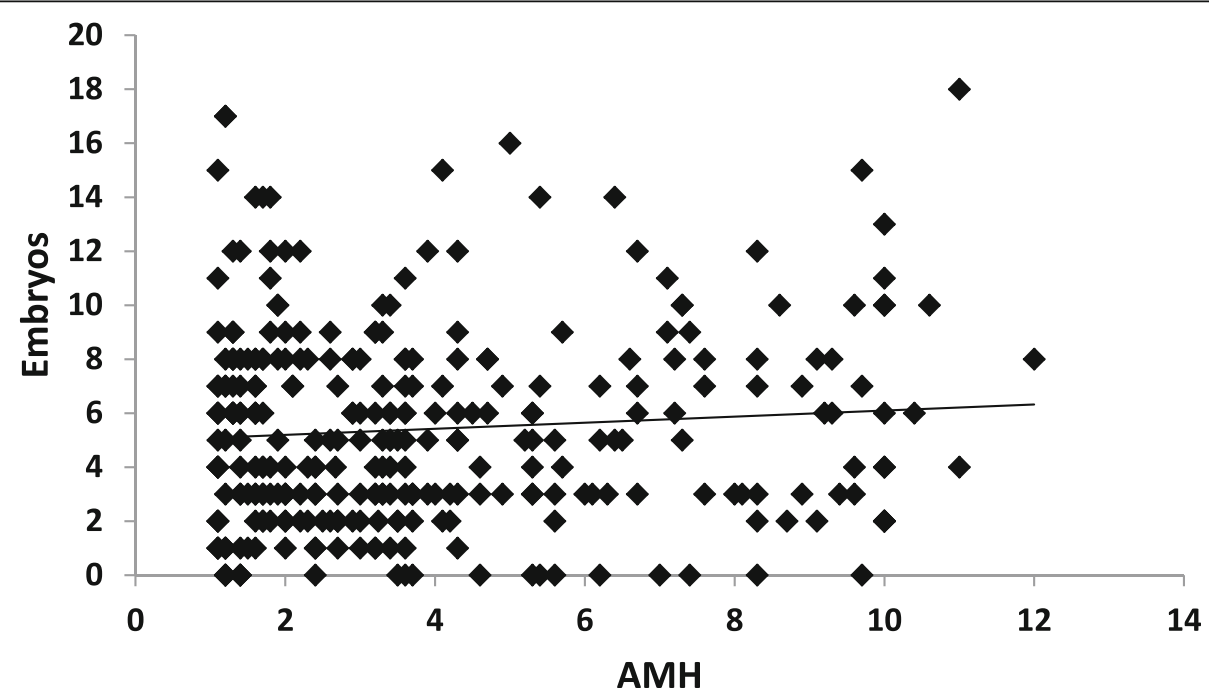

Fig. 4 Correlation between $\mathrm{AMH}$ level and total embryos among cases with $\mathrm{AMH}>1$ 
Table 2 Clinical outcome in low and extremely low AMH

\begin{tabular}{|c|c|c|c|}
\hline & $\mathrm{AMH}<0.5$ & $\mathrm{AMH} 0.5-1$ & $P$ value \\
\hline Number of women & 105 & 201 & \\
\hline Mean AMH (ng/ml) & $0.31 \pm 0.12$ & $0.74 \pm 0.15$ & NS \\
\hline Mean age (years) & $34.39 \pm 5.12$ & $33.48 \pm 4.82$ & NS \\
\hline Mean number of oocytes retrieved & $4.42 \pm 3.38$ & $6.43 \pm 3.7$ & $<0.001$ \\
\hline Mean number of cleaved embryos & $2.77 \pm 2.07$ & $3.86 \pm 2.46$ & 0.001 \\
\hline Number of patients who had embryo transfer & $72(68.6 \%)$ & $156(77.6 \%)$ & NS \\
\hline Clinical pregnancy rate per started cycles & $18(17.1 \%)$ & $42(20.9 \%)$ & NS \\
\hline Live birth rate per started cycles & $12(11.4 \%)$ & $33(16.4 \%)$ & NS \\
\hline
\end{tabular}

A study of 128 women with extremely low AMH concentrations (below $0.4 \mathrm{ng} / \mathrm{ml}$ ), including 70 women aged $<42$ years, resulted in 16 clinical pregnancies and 10 deliveries [12].

Counseling women with extremely low AMH concentrations can be difficult, because the predictive value for $\mathrm{AMH}$ concentrations is not absolute; its false-positive rate may have previously prohibited women from entering an IVF program [12].

In the prediction of a live birth following IVF, a distinction, however moderate, can be made between couples with a good and a poor prognosis. The success of IVF was found to mainly depend on maternal age and serum AMH concentrations, one of the most relevant and valuable markers of ovarian reserve [13]. Age, AMH, AFC, and cause, when subclassified, are independently associated with the results of an IVF/ICSI treatment. These results enable couples to face real expectations in their particular scenario [14].
Women with very low AMH levels $(<0.5 \mathrm{ng} / \mathrm{mL})$ undergoing IVF still have a chance of achieving a pregnancy, but their prognosis is significantly affected by chronological age. Very low AMH levels are associated with a relevant risk of cycle cancelation but should not be considered a reason to exclude a couple from IVF [15].

In young patients with low AMH levels who have good quality embryos, $\mathrm{AMH}$ is not associated with clinical pregnancy, spontaneous miscarriage, or live birth rates [16].

\section{Conclusion}

Our study showed the importance of age in determining prognosis of IVF in patients with low levels of AMH. There was no difference in the outcome of IVF between low and extremely low AMH levels. Women with normal AMH level resulted in higher pregnancy rate as compared to women with low AMH level in the same age group.

Table 3 Clinical data in all patient groups

\begin{tabular}{|c|c|c|c|c|c|c|c|c|c|}
\hline & \multicolumn{3}{|l|}{$<35$ years } & \multicolumn{3}{|l|}{$35-40$ years } & \multicolumn{3}{|c|}{ Above 40 years } \\
\hline & $\mathrm{AMH} \leq 1$ & $\mathrm{AMH}>1$ & $\begin{array}{l}P \\
\text { value }\end{array}$ & $\mathrm{AMH} \leq 1$ & $\mathrm{AMH}>1$ & $\begin{array}{l}P \\
\text { value }\end{array}$ & $\mathrm{AMH} \leq 1$ & $\mathrm{AMH}>1$ & $\begin{array}{l}P \\
\text { value }\end{array}$ \\
\hline Number of women & 156 & 161 & & 113 & 109 & & 37 & 36 & \\
\hline Mean AMH (ng/ml) & $0.61 \pm 0.26$ & $4.36 \pm 2.83$ & $\begin{array}{l}< \\
0.001\end{array}$ & $0.58 \pm 0.23$ & $3.17 \pm 2.35$ & $\begin{array}{l}< \\
0.001\end{array}$ & $0.55 \pm 0.27$ & $2.14 \pm 2.74$ & $\begin{array}{l}< \\
0.001\end{array}$ \\
\hline Mean age (years) & $29.8 \pm 3.23$ & $28.91 \pm 3.87$ & NS & $\begin{array}{l}36.94 \pm \\
1.49\end{array}$ & $36.73 \pm 1.38$ & NS & $41 \pm 1$ & $\begin{array}{l}41.11 \pm \\
1.28\end{array}$ & NS \\
\hline Mean number of oocytes retrieved & $\begin{array}{l}6.36 \pm \\
4.019\end{array}$ & $\begin{array}{l}13.63 \pm \\
6.103\end{array}$ & $\begin{array}{l}< \\
0.001\end{array}$ & $\begin{array}{l}5.15 \pm \\
3.271\end{array}$ & $\begin{array}{l}11.19 \pm \\
5.489\end{array}$ & $\begin{array}{l}< \\
0.001\end{array}$ & $\begin{array}{l}4.86 \pm \\
3.173\end{array}$ & $\begin{array}{l}8.24 \pm \\
4.977\end{array}$ & 0.005 \\
\hline Mean number of cleaved embryos & $3.6 \pm 2.46$ & $6.08 \pm 3.623$ & $\begin{array}{l}< \\
0.001\end{array}$ & $\begin{array}{l}3.47 \pm \\
2.281\end{array}$ & $5.27 \pm 3.174$ & $\begin{array}{l}< \\
0.001\end{array}$ & $\begin{array}{l}3.23 \pm \\
2.471\end{array}$ & $\begin{array}{l}4.05 \pm \\
2.656\end{array}$ & NS \\
\hline $\begin{array}{l}\text { Number of patients who had embryo } \\
\text { transfer }\end{array}$ & $12781.4 \%$ & $206(95 \%)$ & $\begin{array}{l}< \\
0.001\end{array}$ & $74(65.5 \%)$ & $62(98.4 \%)$ & $\begin{array}{l}< \\
0.001\end{array}$ & $26(70.3 \%)$ & $19(73.1 \%)$ & NS \\
\hline $\begin{array}{l}\text { Number of patients with failure of } \\
\text { fertilization }\end{array}$ & $28(17.9 \%)$ & $11(5 \%)$ & $\begin{array}{l}< \\
0.001\end{array}$ & $32(28.3 \%)$ & $1(1.6 \%)$ & $\begin{array}{l}< \\
0.001\end{array}$ & $11(29.7 \%)$ & $6(23 \%)$ & NS \\
\hline Clinical pregnancy rate per started cycles & $40(25.6 \%)$ & $84(38.7 \%)$ & 0.008 & $19(16.8 \%)$ & $24(38.1 \%)$ & 0.002 & $1(2.7 \%)$ & $2(7.7 \%)$ & NS \\
\hline Live birth rate per started cycles & $29(18.6 \%)$ & $72(33.2 \%)$ & 0.002 & $15(13.3 \%)$ & $20(31.7 \%)$ & 0.003 & $1(2.7 \%)$ & $1(3.8 \%)$ & NS \\
\hline
\end{tabular}




\section{Abbreviations}

AMH: Anti-Mullerian hormone; E2: Estradiol; FSH: Follicle-stimulating hormone; GC: Granulose cells; GnRH-a: Gonadotropin-releasing hormone agonist; hMG: Human menopausal gonadotropins; IVF/ICS: In vitro fertilization/intracytoplasmic sperm injection; LBR: Live birth rate; RecFSH: Recombinant follicle-stimulating hormone; TGF: Transforming growth factor

\section{Acknowledgements \\ Not applicable}

\section{Authors' contributions}

YZ collected, analyzed, and interpreted the patients' data. MMA was a major contributor in writing the manuscript. All authors read and approved the final manuscript.

\section{Funding}

Not applicable

\section{Availability of data and materials}

The datasets used and/or analyzed during the current study are available from the corresponding author on reasonable request.

\section{Ethics approval and consent to participate}

Ethical approval was obtained from The Internal Ethical committee of the Egyptian IVF Center in December 2014 (approval number: 2014/017). Written informed consent was obtained from every patient who participated in the research.

\section{Consent for publication}

Not applicable

\section{Competing interests}

The authors declare that they have no competing interests.

\section{Author details}

${ }^{1}$ The Egyptian IVF Center, 3 Street No. 161 Hadayek El-Maadi, Cairo 11431, Egypt. ${ }^{2}$ Faculty of Medicine, Cairo University, Cairo, Egypt. ${ }^{3}$ Faculty of Medicine, AlAzhar University, Cairo, Egypt.

Received: 12 November 2019 Accepted: 31 December 2019

\section{Published online: 15 January 2020}

\section{References}

1. Cate RL, Mattaliano RJ, Hession C, Tizard R, Farber NM, Cheung A et al (1986) Isolation of the bovine and human genes for Mullerian inhibiting substance and expression of the human gene in animal cells. Cell 45:685698

2. Weenen C, Laven JS, Von Bergh AR, Cranfield M, Groome NP, Visser JA et al (2004) Anti-Mullerian hormone expression pattern in the human ovary: potential implications for initial and cyclic follicle recruitment. Mol Hum Rep 10:77-83

3. Aboulghar M, Saber W, Amin Y, Aboulghar MM, Serour G, Mansour R (2014) Impact of antimullerian hormone assays on the outcomes of in vitro fertilization: a prospective controlled study. Fertil Steril 101:134-137

4. Baird DT, Smith KB (1993) Inhibin and related peptides in the regulation of reproduction. Oxf Rev Reprod Biol 15:191-232

5. Nelson SM, Anderson RA, Broekmans FJ, Raine-Fenning N, Fleming R, La Marca A (2012) Anti-Müllerian hormone: clairvoyance or crystal clear? Hum Reprod 27:631-636

6. Kumar A, Kalra B, Patel A, McDavid L, Roudebusls WE (2010) Development of a second generation anti-Müllerian hormone (AMH) ELISA. J Immunil Methods 362:51-59

7. La Marca A, Giulini S, Tirelli A, Bertucci E, Marsella T, Xella S et al (2007) AntiMüllerian hormone measurement on any day of the menstrual cycle strongly predicts ovarian response in assisted reproductive technology. Hum Reprod. 22:766-771

8. Gracia CR, Shin SS, Prewitt M, Chamberlin JS, Lofaro LR et al (2018) Multicenter clinical evaluation of the Access AMH assay to determine AMH levels in reproductive age women during normal menstrual cycles. J Assist Reprod Genet. 35(5):777-783
9. Broer SL, van Disseldorp J, Broeze KA, Dolleman M, Opmeer BC, Bossuyt $P$ et al (2013) IMPORT study group. Added value of ovarian reserve testing on patient characteristics in the prediction of ovarian response and ongoing pregnancy: an individual patient data approach. HumReprod Update 19:26-36

10. Lukaszuk K, Kunicki M, Liss J, Bednarowska A, Jakiel G (2014) Probability of live birth in women with extremely low anti-Müllerian hormone concentrations. Reprod Biomed Online 28:64-69

11. Borges E, Braga DPAF, Setti A, Figueira RC, laconelli A Jr (2017) The predictive value of serum concentrations of anti-Müllerian hormone for oocyte quality, fertilization, and implantation. JBRA Assist Reprod. 21(3):176-182

12. Weghofer A, Dietrich W, Barad DH, Gleicher N (2011) Live birth chances in women with extremely low-serum anti-Mullerian hormone levels. Hum Reprod 26:1905-1909

13. La Marca A, Nelson SM, Sighinolfi G, Manno M, Baraldi E, Roli L et al (2011) Anti-Mullerian hormone-based prediction model for a live birth in assisted reproduction. Reprod Biomed Online. 22(4):341-349

14. Metello JL, Tomás C, Ferreira P (2019) Can we predict the IVF/ICSI live birth rate? JBRA Assist Reprod 23(4):402-407

15. Revelli A, Biasoni V, Gennarelli G, Canosa S, Dalmasso P, Benedetto C (2016) IVF results in patients with very low serum $\mathrm{AMH}$ are significantly affected by chronological age. J Assist Reprod Genet. 33(5):603-609

16. Pereira N, Setton R, Petrini AC, Lekovich JP, Elias RT, Spandorfer SD (2016) Is anti-Müllerian hormone associated with IVF outcomes in young patients with diminished ovarian reserve? Womens Health (Lond) 12(2):185-192

\section{Publisher's Note}

Springer Nature remains neutral with regard to jurisdictional claims in published maps and institutional affiliations.

\section{Submit your manuscript to a SpringerOpen ${ }^{\circ}$ journal and benefit from:}

- Convenient online submission

- Rigorous peer review

- Open access: articles freely available online

High visibility within the field

- Retaining the copyright to your article

Submit your next manuscript at $\boldsymbol{\nabla}$ springeropen.com 